\title{
Online Counselling Support in Australian and New Zealand Universities
}

\author{
Brad Inglis \\ Counselling Service \\ Southern Cross University \\ Kellie Cathcart \\ Independent Clinical Psychologist \\ $\&$ former Online Counsellor \\ University of Newcastle
}

\begin{abstract}
The higher education sector is currently undergoing a major shift towards increasing the amount of courses that are taught online, hence there is also a growing need to provide support services for online students. This paper reports on the results of a survey that aimed to gather information on the online presence of counselling services across Australian and New Zealand higher education facilities. It indicates that movement towards offering online counselling support for students is slow, with services and professionals showing some resistance to, and anxiety around, moving into this sphere. Where services have been offered, there is little consistency across the sector. A number of challenges around engagement, marketing, technology and clinician anxiety have hampered successful outcomes. There have been notable exceptions to this, with a few universities trialling different online platforms and engagement strategies with students, with varying levels of success. Overall there appears to be a need for counsellors to be offered training in providing online services to students; not only to increase their confidence in providing these services, but also to help to change attitudes about online mental health services. There is also a need for more research into the efficacy of those models which are operating successfully, in order to encourage change in clinician attitudes, which in turn may lead to further adoption of online services across the sector.
\end{abstract}

\section{Introduction}

This paper reports on the results of a survey that aimed to gather information on the online provision of counselling in Australian and New Zealand universities. In recent years universities have provided an increasing number of courses online and subsequently many students can now study their degree whilst spending very little time on campus. There have been many developments in the provision of online counselling support and mental health care in the public and private sectors more broadly, however very little has been reported on initiatives in universities.

For the purpose of the discussion within this paper, the term 'online counselling support' refers to a wide range of technologies used for the provision of therapy, information sharing and service promotion within university counselling services. These include use of email and videoconferencing software, social media platforms, interactive websites, and instant chat. Interventions vary by level of therapist support; from those which are entirely self-directed, where the participant can read, watch, and listen to information which they can independently implement in their lives; to those which are more clinician-directed, for example with weekly phone or email contact directing and supporting the client's involvement. Also, the structure of the work varies, including those interventions which follow a specified, often manualised, step-by-step process and those providing non-directive therapy or counselling.

The aims of the survey were to identify the prevalence of the use of online technologies within Australian and New Zealand university counselling services; also, to gain insight into the successes and difficulties in providing these methods of support, including consideration of practitioner and institutional perspectives. 


\section{Mental health support in Australia}

The impact of mental distress on individual wellbeing and the functioning of society more generally, is being increasingly recognised (Trautmann, Rehm, \& Wittchen, 2016; World Health Organisation, 2008). It is now well documented that a large proportion of the population will at some point meet criteria for the diagnosis of a mental disorder, with the highest prevalence rates in young adults (Slade et al., 2009). In Australia, direct costs of psychological support, medications, and hospital admissions, in addition to indirect costs in the form of decreased work productivity, absenteeism, and welfare payments, are estimated to cost over $\$ 28$ billion per annum (OECD, 2015). Unfortunately, despite there being some increases in the availability of psychological support within the Australian healthcare system, information from the Australian Bureau of Statistics (ABS) in 2007 showed that only approximately $35 \%$ of people who experienced a mental disorder within Australia sought professional support. More recent overseas data shows similar rates for those with serious suicidal thoughts, with just under $40 \%$ seeking support (SAMSAH, 2012).

One way in which governments and non-government organisations have attempted to improve access to professional support has been the introduction of online support. National mental health services, Headspace, Lifeline and Youthline, are examples of services providing support using synchronous chat (live online chat), online support groups and self-directed modules. Funding has also been recently announced in Australia for Medicare rebated videoconference sessions with psychologists for those living in rural and remote areas; complementing already established teleconference support by psychiatrists (Department of Health, 2017).

\section{Mental health in Australian universities}

Awareness has gradually increased regarding the particularly high levels of mental distress in the Australian university student population. Research by Helen Stallman (2010) provided a foundation for a greater focus in this area with her comparison of psychological distress levels in university students with that of the general public. Stallman's article has now been extensively cited and has received coverage in news media within Australia and internationally. Stallman's findings indicate that approximately $84 \%$ of university students are experiencing elevated levels of mental distress: a significantly higher level than the approximately $29 \%$ estimated to be experiencing this level of distress in the general Australian population (Stallman, 2010). Furthermore, Stallman (2008) has reported elsewhere that very high mental distress has a substantial impact on the ability of those suffering, to work and study.

In addition to the low level of professional help-seeking aforementioned, efforts to support the mental health of university students are complicated by a shift in the nature and delivery of university study. Online courses have allowed a wide array of students who may have previously been unable to attend on-campus study, due to location or other commitments, to access a variety of university courses. However, the same factors also preclude online students from accessing oncampus support services.

\section{Provision of online mental health and wellbeing services}

It is worth noting that there also appears to be a trend or preference toward seeking support online, even for those who can access face to face services. Mission Australia's recently released Youth 2016 report indicates that almost half of young people who seek personal support do so via the internet. Glasheen, Shochet, and Campbell (2016) also reported a high level of interest in online support from Australian high school students. The authors report that over $80 \%$ of the high school students who participated in their research, indicated they would, or might, access online counselling if offered by the school counsellor. This study also reports a relative increase in males 
being interested in seeking online counselling support, compared with face to face support.

Ryan, Shochet, and Stallman (2010) similarly report an increased preference for Australian university students to use online support during times of high distress. In the research they conducted with university students, they reported that almost $60 \%$ of respondents with high levels of psychological distress expressed intention to access online support. The authors subsequently concluded that "online interventions may be a useful way to provide help to students in need who otherwise may not seek formal help" (p.1).

Reflecting the shifting preferences reported above, many Australian and New Zealand universities have begun implementing online counselling services, with some forms of tele-conference and email support being those most commonly promoted (Cathcart, 2016; Mullin et al., 2014).

\section{Current evidence for effectiveness of online counselling}

Work at the Macquarie University eCentre Clinic has produced promising results for an online wellbeing program, coupled with clinician contact via phone or secure e-messaging service (Mullin et al., 2014). The treatment group (those who received support through the program) showed significant reductions of clinical levels of anxiety and depression symptoms compared with the control group (those on the waitlist) at post-treatment and at three-month follow-up. Whilst results are promising, the number of participants in this study is small, and some limitations regarding sampling method are reported. Similarly, a review of online programs by Davies, Morriss, and Glazebrook (2014) reports some promising results but their review also found many methodological flaws with population sampling, small numbers, or the non-inclusion of a control group.

In the broader community there is a growing body of research examining online psychological interventions. The National Drug and Alcohol Research Centre in Australia has conducted numerous trials on the effectiveness of a range of electronic Cognitive Behavioural Therapy (eCBT) programs for reducing comorbid depression and substance use (Deady, Mills, Teesson, \& Kay-Lambkin, 2016; Kay-Lambkin et al., 2015) as well as increasing healthy lifestyle behaviours (Baker et al., 2011). Similarly, there has been success in using eCBT for anxiety and depression (Andersson \& Cuijpers, 2009; Cuijpers et al., 2009; Cuijpers, Donker, van Straten, Li, \& Andersson, 2010), and internet-delivered manualised interventions for depression (Wagner, Horn, \& Maercker, 2014), and PTSD (Lappaleinen et al., 2014).

\section{Study Objectives}

Given the limited amount of published research about online services within Australian and New Zealand university counselling services, the foremost purpose of the current study was to determine a baseline of current service provision. Furthermore, in the interest of sharing as much information as possible with the Australian and New Zealand higher education support services sector, it was considered important to collect any evidence of effectiveness of interventions, where available, and to explore the attitudes and concerns of university-based counsellors about the provision of online services.

\section{Method}

\section{Survey}

A survey for university counselling staff was developed by the researchers with three separate sections: 1) details of online services offered both currently and in the past; 2) perceptions and/or evidence regarding successes and limitations of these, including staff attitudes towards any online services trialled; and 3) demographic details of the university, number of campuses and number of students. 
Questions specifically about the online counselling presence provided by the service, both current and past, along with participant attitudes towards this, were asked at the commencement of the survey. A full copy of the survey can be found in Appendix A.

\section{Participants}

Participants were sought from amongst those who work within Australian and New Zealand higher education counselling services. They were recruited in three different ways: 1) an advertisement via the newsletter of the Australian and New Zealand Student Services Association (ANZSSA); 2) an email invitation from the President of the ANZSSA Heads of Counselling Group; and 3) an e-mail invitation sent to each counselling service across all Australian and New Zealand Universities. Altogether, 47 institutions across Australia and New Zealand were contacted. Participants could be any employee of the university counselling service, not limited to clinicians, in order to increase the response rate. In order to increase anonymity, the specific demographics of the participant, such as role, gender, age, ethnicity, were not obtained.

Each participant was provided with a link to the online survey described above. Participants were given the option of anonymously completing the survey in part or full, and also the opportunity to have their responses withdrawn from inclusion in the results to be publicly disseminated through conference presentation and publication.

\section{Data analysis}

All qualitative data were analysed through thematic analysis, employing a widely used method for exploratory qualitative research, whereby the responses were read, re-read and common themes and sub-themes were identified and subsequently named (Attride-Stirling, 2001; Carrera-Ferdandez, Guàrdia-Olmos, \& Pero-Cebollero, 2014). Table 1 demonstrates an example of this process.

Table 1 Example of coding process

\section{Survey responses Initial Coding Framework}

\section{What Works Well}

\footnotetext{
"Structured, targeted approach to 'homework"

"Communicate about social anxiety that prevents them from initially making a face-to-face appointment"
}

\section{Barriers and Limitations}

"Limited time available to successfully promote some things"

"Internet speed of user"

\author{
Capacity \& Power \\ Reduced Barriers
}

Poor Quality and Resourcing

Technology

\section{Results}

\section{Respondents}

There were 38 respondents who completed the survey, two of whom did not consent to their responses being used in analyses and were therefore removed. Respondents were counsellors, service managers, and other staff associated with counselling services from 20 universities across Australia and New Zealand. A further three did not indicate their university. Of those who identified their university there were 19 out of a possible 39 from Australian campuses, one out of eight New Zealand universities and an overall response rate of $43 \%$. The response rate is quite high 
for survey participation and the numbers adequate for the level of analysis used within this research. A large variety of universities were represented; predominately they were large, multi-campus institutions offering courses at undergraduate and postgraduate levels.

Survey responses revealed information regarding the counselling services in which the participants worked. Most services included multiple counsellors (mean=5.97, SD=2.03), and predominantly permanent staff. The vast majority provided a selection of face to face counselling, drop-in sessions, workshops, and participation in other events on their campus. Wait times reported for counselling varied from one or two days, to three weeks.

\section{Current online offerings}

Twenty-five respondents reported regularly referring students to online self-help resources, 20 reported referral to smartphone applications and 17 reported referral to e-mental health websites. Video (for example, Skype) sessions were also reported by 12 respondents as an alternative method of contact, while 17 mentioned email. Furthermore, nine reported trialling Webinars, nine had set up Facebook pages, nine had developed online question and answer sites (Q\&A), while five had used blogs. This reflects the growing trend for universities to be offering their students online support, such as Western Sydney University's 'eCounselling' (Western Sydney University, 2017) and the University of Newcastle's Online Skype Counselling (University of Newcastle, 2018).

\section{Success of current offerings}

Analysis of qualitative data from the survey revealed multiple themes on the topic of what has worked well for current online offerings. Themes were determined when four or more responses indicated a similar idea. These are outlined below:

Capacity \& Power: This included comments about the power, quality and subsequently positive results of using online support services. Comments included references to the ability to provide more structured support, to reflect on past session content, and capacity to gain quality outcome data.

Accessibility \& Reach: Responses related to a perceived increase in the accessibility of offering online services, compared with offering on-campus services only. Convenience, equity and flexibility were all reported as positive aspects of online services.

Diversity: These responses made particular mention of the way that providing online support options improved the diversity of their service, allowing students a greater ability to choose how they access support.

Reduced Barriers: Responses specifically reported the benefit of providing students with an accessible first contact point, particularly for those who are quite anxious and hesitant about the prospect of entering a counselling environment. The potential for anonymity was included here.

Speed \& Triage: Many responses also referred to the benefits of some online services which allowed concerns to be dealt with more quickly, particularly those that did not end up requiring counselling intervention and could be more speedily triaged.

\section{Difficulties of current offerings}

The repeated themes that emerged in relation to what has been difficult, or barriers to using online support, were as follows:

Poor Quality and Resourcing: Poor quality of the services offered, along with inadequate promotion, were mentioned as significant barriers to the effective operation of online services. Specifically, a lack of resourcing to promote services was reported, and a lack of quality in some 
online services accessed. One respondent reported that their service was "self-help only, not a real online service" and another commented, "limited time available to successfully promote..."

Practitioner Difficulties: Some practitioners (counsellors) reported difficulties adapting their skills for use in the online environment, including being unable to access non-verbal information.

Suitability / Severity Issues: These included concerns about high-risk clients and the related legal concerns in their management. Multiple respondents indicated a concern with severe, risky and complex presentations coming through email.

Technology: Comments related to technological issues; specifically, internet speed and various other technical difficulties impacting on the support offered.

Low Uptake \& Reach: A small sample of comments referred to difficulties establishing adequate reach (for example in promoting services via social media) as well as students' lack of interest in online support.

Student Preference: A number of comments also mentioned a reluctance in some students to engage in online support options. A desire for face to face, where available, was mentioned in multiple responses.

\section{Previously offered online interventions}

Of the universities which responded, 19 indicated no changes in their service; that is, they had either not offered any online services to students, or had continued to offer the online services they had been offering for some time and had not ceased using any. Seven universities reported trying one or more online interventions, which they no longer use. The most commonly trialled and abandoned was Skype individual appointments. The reasons given for no longer offering these appointments was a lack of security and information technology (IT) infrastructure to support the service, as well as a concern about indemnity insurance limitations when the students were located overseas. Comments included: "online security and confidentiality concerns and lack of IT infrastructure" and "We sometimes did this for students overseas - advised that insurance and registration status is not valid when providing counselling services to students when they are located overseas."

E-mail counselling was trialled and discontinued by two universities, with a participant from one of these indicating that a lack of support from counselling staff resulted in the students being encouraged to use face-to-face services instead. This participant commented: "Advertised email counselling, but reality was that counsellor just encouraged students to attend in person."

A Q\&A site and two blogs were also discontinued, with a participant at one university indicating there was a lack of time and resources to continue with the service, as it was seen as a lower priority than face-to-face services. "Resources - blogging takes time staff don't have! Often not seen as a priority amongst other more pressing issues." Other services which were trialled and discontinued included live webinars, Facebook pages, and referrals to e-mental health resources.

\section{Engagement strategies}

Figure 1 below outlines the frequency of use of specific promotion strategies across the 39 responses for this question. The more popular strategies used were: attendance at student events on campus; advertising on university and counselling webpages; and building staff awareness. Additional strategies mentioned by respondents included: guest lectures to students; posters on campus; and e-mail communication with current clients of the service. 


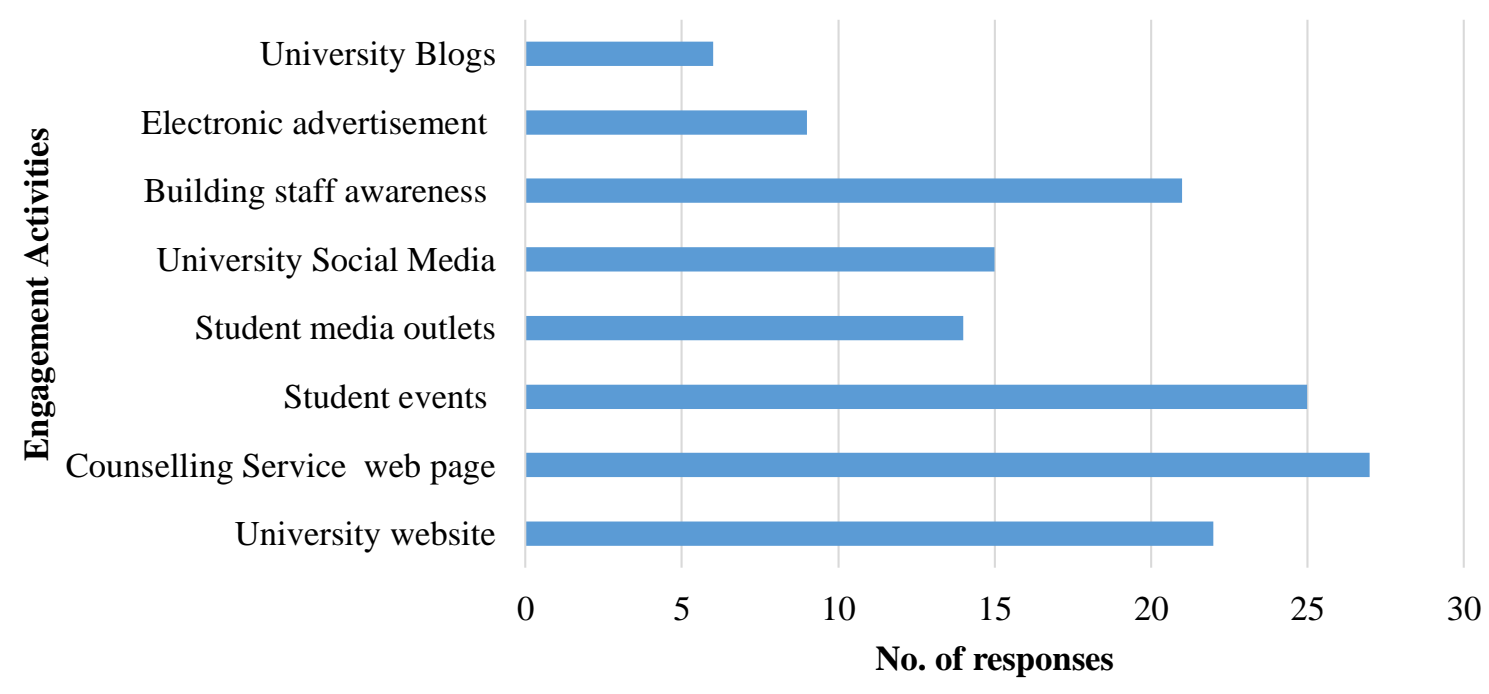

Figure 1. Engagement strategies used to engage students in online services

Only 19 respondents indicated a level for success of the strategies used, with $37 \%$ of these $(n=7)$ indicating a high level of success, as evidenced by an increase in numbers and high demand for services: 'Excellent! Using student communications teams' Twitter, Instagram and Facebook page allows for access to more than 20,000 audience. Staff awareness and networking has really helped also." And "Each year we have an increase in students accessing online counselling."

Four participants indicated a moderate success, while two others indicated low levels of success.

"It has been a slow uptake! Intermittent - needs to be strategically targeted but hard when there is so much information they get given" and, "Reasonably successful. But constant and ongoing promotion required."

Three said they were unable to comment as they indicated they were not specifically collecting data on how students were referred to the service.

Respondents indicated difficulties with their current promotion strategies, including a lack of awareness of the services, limited resources, and a resistance from the practitioners within the counselling service. A number of responses given here were reflective of a wider issue - that of the attitude and skills of staff in offering online services, rather than difficulties with the engagement strategies themselves. For example, there were reports of difficulty in building rapport and communicating effectively with students using online technologies, as well as technical difficulties around engagement in the actual services themselves. There were also attitudes expressed about face-to-face counselling being superior to that delivered online.

\section{Beliefs and attitudes}

In response to the question about whether they would be interested in offering online services at their campus, 21 participants reported that they would, although six added that they would only do so if training and adequate resources were provided. Only two participants indicated they were not interested in offering online services while 13 did not answer. The remainder of participants indicated that they were already offering online counselling.

When asked what concerns they had about providing online services, the most common concern raised was difficulty with technology. "Getting staff up to speed with technology is a big issue". 
Following this, the biggest concern raised was difficulty engaging in a therapeutic relationship with clients, possibly also linked to the concern mentioned earlier about a lack of skills and training in offering online counselling. Six participants said they had no concerns. Figure 2 below illustrates the range of responses.

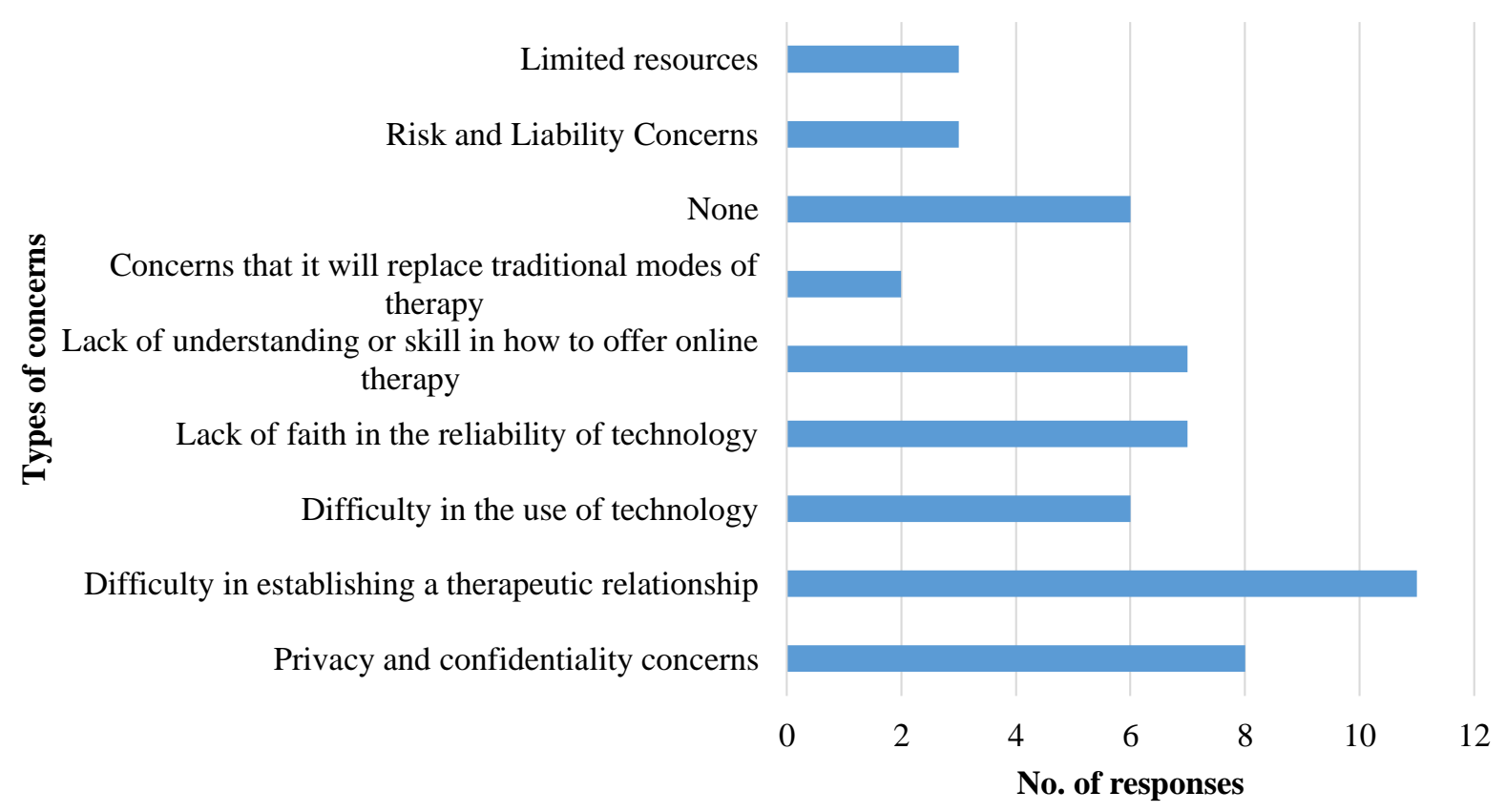

Figure 2. Concerns about offering online therapy

Again, participants indicated some concern for the client's safety when they were identified as being at risk, "Only concerns continues to be what happens if you are working with a student who is in a different country and they report a risk of harm to themselves or others, particularly children."

\section{Discussion}

The growing awareness of mental health issues amongst the general Australian population is reflected in the expansion of existing public and private mental health services, as well as the development of new services. As previously mentioned, research indicates that the prevalence of mental health issues in Australia is higher amongst the student population studying at tertiary facilities than amongst the general population, with approximately $84 \%$ of university students experiencing elevated levels of mental distress compared with $29 \%$ of the general population (Stallman, 2010). However, despite these concerning rates, the percentage of students seeking help through university counselling services is much lower. This, coupled with a shift towards more online university academic programs, in which students are working and studying simultaneously, has forced the university sector to consider alternative pathways to providing support for students in distress. Given the growing popularity of e-mental health services and the familiarity of students with electronic resources, it is perhaps not surprising that many respondents indicated that their university is either offering, has offered, or is contemplating offering online counselling services to accommodate the needs of their students.

The survey results confirmed that universities are moving into the e-mental health space, with a wide range of services being offered across campuses, ranging from blogs, Q\&A e-mail services, online video, audio and text audio chats, e-mail sessions and referrals to self-directed and clinically assisted applications and programs. Participants repeatedly mentioned the greater flexibility and 
accessibility of e-mental health services. Given the increasing number of students studying online, this has implications for greater equity in service provision for those who are less able to access oncampus connections and support services, which may in turn place them at higher risk of distress.

Several participants indicated that their institutions had discontinued one or more of their e-mental health services for students. The reasons for this varied but fell across two main categories, that of a lack of uptake from students and a lack of resources available to support the service. Whilst it has been reported that e-mental health options are a cost-effective method of offering services to a more geographically and socially diverse population (Andersson \& Titov, 2014; Hedman et al., 2012), the initial start-up costs required for hardware, software and clinician training can perhaps be a barrier. In an environment where tertiary support services are stretched, resources may be directed towards maintaining existing services rather than establishing new services, even though these could be potentially more far-reaching.

Another barrier identified by respondents was the lack of awareness, amongst students, of the services available, with a consensus that promotion of the services needs to be ongoing. This is consistent with other evidence of a lack of awareness amongst the general population, of mental health services, what they are and how to access them (Gulliver, Griffiths, \& Christensen, 2010). Promotion of e-mental health services amongst student populations requires dedicated time and resources and needs to be implemented across a number of platforms. Lack of assistance from other departments, such as technical support from IT staff, was also mentioned as a difficulty in offering the services. Participants who reported higher success appeared to be working at institutions which were implementing a number of different engagement activities and had assistance from other departments.

Despite increasing evidence to suggest that retention of students is significantly increased when they are provided with adequate support from services such as counselling (Munro, Campbell, \& Graham, 2015) respondents indicated a lack of shared purpose and drive between academic, professional and counselling staff, which in some cases resulted in e-mental health services being discontinued. One example was the lack of adequate software to ensure privacy and confidentiality. Similar to face-to-face counselling environments, online environments must be able to address any concerns regarding privacy and confidentiality for clients accessing these services. A lack of support from staff within IT departments was identified, particularly around the level of software security deemed to be sufficient. This was sometimes due to a lack of resources, such as infrastructure funding, or at other times disagreement about the threshold for security of software required. The lack of highly secure software inevitably limits the feasibility of offering online counselling services. Interestingly, the potential barriers of privacy and confidentiality concerns have been successfully negotiated within the public health, non-government and private sectors which offer e-mental health services, including online psychological therapy under the Australian Medicare 'Better Outcomes in Mental Health' initiative offered to the general population. This suggests that the challenges are not insurmountable and that further work between university departments could resolve these issues.

The other barrier to offering e-mental health services was that of the beliefs and the attitudes of existing counselling staff. These concerns lay mainly with a lack of skill and confidence in offering the services, specifically how to build therapeutic rapport in an online environment and to a lesser degree how to manage risk. These could potentially be resolved with additional training that assists staff to understand what is available, how to use their existing skills in the new environment, and allows them time to practise the skills before implementing them. For example, much of the evidence in the literature to date has focused on the manualised self-directed and clinically assisted programs used to treat depression and anxiety within this population (Barak, 2007; Lappeleinen et 
al., 2014; Wagner et al., 2014). However, few participants indicated they used these types of programs with their clients. Whilst this could be due to a lack of awareness or experience with these programs, it could also reflect a lack of confidence in e-mental health strategies, which could potentially be addressed in the provision of both training and time to explore and use the programs themselves.

Additional research is also required to explore further the influence of clinicians' attitudes and beliefs towards online methods and on their willingness to use such tools. Furthermore, conclusions must be drawn tentatively at this stage, with further research to focus on a more in-depth exploration of the issues involved and a larger sample size required, especially from New Zealand universities.

\section{Conclusion and implications for practice}

For university counselling services to successfully develop and implement a suite of studentspecific e-mental health services comparable to or exceeding those available to the general population, the following recommendations are made, on the basis of the findings from this survey. Institutions need to:

- Allocate time and resources to researching types of e-mental health services that are available and would best complement their existing counselling service and student population. There is also a need to consider the utilisation of existing products and programs that may be purchased or re-branded to be part of the suite rather than 'reinventing the wheel'.

- Allocate a budget to invest in the set-up of hardware, software and training of staff and students in the use of these products, to enhance uptake of the services.

- Allow adequate time and resources for the development and set-up of the services being offered. This should include staff training, not only in the use of technology, but also in the development of therapeutic skills in synchronous and asynchronous methods of delivery.

- Implement promotion and engagement strategies with both students and staff, alongside the e-mental health services. A lack of awareness of services can be a major source of failure.

- Develop a comprehensive evaluation plan for all elements of the service. The plan should look at uptake, promotion strategies, experience and effectiveness of the services being offered. Not only will this help guide the future direction of the services being offered, but it will also contribute to the wider research of e-mental health across tertiary education facilities.

Overall, survey results indicate both an interest in and movement towards offering e-mental health services as part of a suite of services and supports for students. Whilst e-mental health services have been available to the general community for some time now, through phone lines, chat services, and online programs, higher education institutions within Australia and New Zealand are only just starting to move towards these types of services. To date, there has been a lack of consistency in approach, with most universities just dipping their toes into these waters and trialling one or two methods with no formal promotion or evaluation strategies, hence hindering the identification of success. The lack of money and resources allocated to this area leads to difficulty in providing and building the services, as well as difficulty for clinical staff members in feeling confident and engaged with the services. Additional time and resourcing in planning and setting up services, including the training of staff, could assist in not only providing a consistent approach across universities, but also in providing a platform for more formal research into the effectiveness of emental health services for the university student population. 


\section{References}

ABS, (2007). National survey of mental health and wellbeing: Summary of results. Commonwealth of Australia. Retrieved from: http://www.abs.gov.au/ausstats/abs@.nsf/mf/4326.0

Andersson, G., \& Cuijpers, P. (2009). Internet based and other computerised psychological treatments for adult depression: a meta-analysis. Cognitive Behaviour Therapy, 38, 196-205.

Andersson, G., \& Titov, N. (2014). Advantages and limitations of Internet-based interventions for common mental disorders. World Psychiatry, 13(1), 4-11.

Attride-Stirling, J., (2001). Thematic networks: an analytic tool for qualitative research. Qualitative Research, 1(3), 285-405.

Baker, A., Kay-Lambkin, F.J., Richmond, R., Filia, S., Castle, D., Williams, J., \& Lewin, T.J. (2011). Study protocol: A randomised controlled trial investigating the effect of a healthy lifestyle intervention for people with severe mental disorders. BMC Public Health, 11(10), 1-8.

Barak, A. (2007). Emotional support and suicide prevention through the Internet: A field project report. Computers in Human Behavior, 23, 971-984.

Carrera-Fernández, M.J., Guàrdia-Olmos, J., \& Peró-Cebollero, M. (2014). Qualitative methods of data analysis in psychology: An analysis of the literature. Qualitative Research, 14 (1), 20-36.

Cathcart, K. (2016). Online counselling: A new landscape for university counselling Services. Journal of the Australian and New Zealand Student Services Association, 47, 87-92.

Cuijpers, P., Marks, J.M., van Straten, A., Cavanagh, K., Gega, L., \& Andersson, G. (2009). Computer-aided psychotherapy for anxiety disorders: A meta-analysis review. Cognitive Behaviour Therapy, 38, 66-82.

Cuijpers, P., Donker, T., van Straten, A., Li, J., \& Andersson, G. (2010). Is guided self-help as effective as face-to-face psychotherapy for depression and anxiety disorders? A systematic review and meta-analysis of comparative outcome studies. Psychological Medicine, 40, 1943-1957.

Davies, E.B., Morriss, R., \& Glazebrook, C. (2014). Computer-delivered and web-based interventions to improve depression, anxiety and psychological well-being of university students: a systematic review and metaanalysis. Journal of Medical Internet Research, 16(5), e130, 1-22.

Deady, M., Mills., K.L., Teesson, M., \& Kay-Lambkin, F. (2016). An online intervention for co-occurring depression and problematic alcohol use in young people: Primary outcomes from a randomized controlled trial. Journal of Medical Internet Research, 18(3), e71, 1-12.

Department of Health (2017). Budget to deliver telehealth boost for rural psychological services [Press release]. Retrieved from: http://www.health.gov.au/internet/ministers/publishing.nsf/Content/health-mediarel-yr2017hunt035.htm

Glasheen, K.J., Shochet, I., \& Campbell, M.A. (2016). Online counselling in secondary schools: would students seek help by this medium? British Journal of Guidance \& Counselling, 44(1), 1-21.

Gulliver, A., Griffiths, K.M., \& Christensen, H. (2010). Perceived barriers and facilitators to mental health help-seeking in young people: A systematic review. BMC Psychiatry 10(113), 1-9.

Hedman, E., Ljotsson, B., \& Lindefors, N. (2012). Cognitive behavior therapy via the Internet: a systematic review of applications, clinical efficacy and cost-effectiveness. Expert Review of Pharmacoeconomics \& Outcomes Research, 12(6), 745-764.

Kay-Lambkin, F.J., Baker, A.L., Geddes, J., Hunt, S.A., Woodcock, K.L., Teesson, M., \& Thornton, L. (2015). The iTreAD project: A study protocol for a randomised controlled clinical trial of online treatment and social networking for binge drinking and depression in young people. BMC Public Health, 15(1025), 1-9.

Lappalainen, P., Granlund, A., Siltanen, S., Ahonen, S., Vitikainen, M., Tolvanen, A., \& Lappalainen, R. (2014). ACT Internet-based vs face-to-face? A randomized controlled trial of two ways to deliver Acceptance and Commitment Therapy for depressive symptoms: an 18-month follow-up. Behaviour Research and Therapy, 61, 43-54.

Mullin, A., Dear, B.F., Karin, E., Wootton, B.M., Staples, L.G., Johnston, L.,... Titov, N. (2015). The UniWellbeing course: A randomised controlled trial of a transdiagnostic internet-delivered cognitive behavioural therapy (CBT) programme for university students with symptoms of anxiety and depression. Internet Interventions, 2(2), 128-136. 
Munro, J., Campbell, D., \& Graham, I. (2015). The role of student counselling in SCU retention strategy: A business case for additional investment. ANZSSA Conference Proceedings, Tasmania Australia. Retrieved from: http://www.conferencedesign.com.au/anzssa2015/papers/anzssa2015Abstract00015.pdf

OECD, (2015). Mental Health and Work: Australia, OECD Publishing, Paris. Retrieved from: https://read.oecdilibrary.org/employment/mental-health-and-work-australia_9789264246591-en\#page1

Ryan, M. L., Shochet, I. M., \& Stallman, H. M. (2010). Universal online interventions might engage psychologically distressed university students who are unlikely to seek formal help. Advances in Mental Health, 9(1), 73-83.

Slade, T., Johnston, A., Teesson, M., Whiteford, H., Burgess, P., Pirkis, J., Saw, S. (2009). The Mental Health of Australians 2. Report on the 2007 National Survey of Mental Health and Wellbeing, Department of Health and Ageing, Canberra.

Stallman, H.M. (2008), Prevalence of psychological distress in university students--implications for service delivery. Australian Family Physician, 37(8), 673-677.

Stallman, H. M. (2010). Psychological distress in university students: A comparison with general population data. Australian Psychologist, 45(4), 249-257.

Substance Abuse and Mental Health Services Administration (SAMHSA). (2014). Half of adults with serious thoughts of suicide did not receive mental health services. Retrieved from http://www.samhsa.gov/data/sites/ default/files/spot136-suicide-services-2014.pdf

Trautman, S., Rehm, J., \& Wittchen, H. (2016). The economic costs of mental disorders. Science and Society; 17(9), 1245-1249.

Wagner, B., Horn, A.B., \& Maercker, A. (2014). Internet-based versus face-to-face cognitive-behavioral intervention for depression: a randomized controlled non-inferiority trial. Journal of Affective Disorders, 152, 113-121.

World Health Organization (2008). The Global Burden of Disease: 2004 Update. Geneva, Switzerland: WHO Press, 2008.

University of Newcastle (2018). Online Counselling. Retrieved from https://uonblogs.newcastle.edu.au/ onlinecounselling/

Western Sydney University (2017, September). eCounselling. Retrieved from https://www.westernsydney.edu.au /currentstudents/current_students/services_and_facilities/counselling_services/ecounselling

The authors may be contacted via:

Brad.Inglis@scu.edu.au

\section{Please cite this paper as:}

Inglis, B., \& Cathcart, K. (2018). Online counselling support in Australian and New Zealand universities. Journal of the Australian and New Zealand Student Services Association. 26(2), 99-112.

https://doi.org.10.30688/janzssa.2018.11 


\section{Appendix A}

\section{Survey Questions}

Q1. Do you consent to the information provided being used anonymously in the preparation of results for publication?

$\square$ Yes $\square$ No

Q2. Do you consent to the information provided being used anonymously in the development of a workshop?

$\square$ Yes $\square$ No

Q3. What online counselling services are you currently offering students at your university?

$\square$ Individual Skype sessions $\quad \square \quad \square \quad \square$ Individual BlackBoard sessions

E-mail sessions $\quad \square \quad \square$ Question \& Answer service

Blog $\square \quad \square$ Online webinars and workshops

online skype drop-ins $\quad \square \quad \square$ Facebook pages

Referrals to e-mental health resources $\square \square$ Referrals to smart device applications

Referrals to self help online resources $\quad \square$ none

Q4. For each of the services you are currently offering could you please provide a short description of how the services operate?

Q5. For each of the services you are currently offering could you please provide a short description of what works well for them?

Q6. For each of the services you are currently offering could you please provide a short description of what the limitations or barriers have been?

Q7. What engagement or promotion strategies are you using to encourage participation from students?

$\square$ Information on the university website about the service

Information on the counselling web pages about the service

Promotion at student events on campus

Promotion in student media outlets (organisations, print publications, electronic media)

University operated Facebook pages

Building staff awareness of the service

Electronic advertisement across campus

University Blogs

Q8. How successful have your promotion strategies been in increasing engagement with students?

Q9. What difficulties have you encountered in engaging with students online?

Q10. What if any concerns do you have about offering online counselling services to students?

$\square$ Privacy and confidentiality

Difficulty in establishing a therapeutic relationship

Difficulty in the use of technology

Lack of faith in the reliability of the technology

Lack of understanding or skill in how to offer online therapy

Concerns that it will replace traditional modes of therapy

none

other

Q11. If your university offered online counselling services to students, would you be interested in providing these?

$\square$ Yes $\square$ No $\quad \square$ Unsure $\square \square \quad \square$ Yes but only if training was provided $\quad \square \square$ Other

Q12. If you answered yes to Question 11 could you elaborate on your reasons for this?

Q13. What if any online counselling services have you offered in the past but no longer offer?
$\square$ Individual Skype sessions
$\square$ Individual BlackBoard sessions

E-mail sessions

Blog

Question \& Answer service

$\square$ Online webinars and workshops 
$\square$ online skype drop-ins

Referrals to e-mental health resources $\square \square$ Referrals to smart device applications

Referrals to self-help online resources none

Q14. If you stopped offering one of these services in questions 13 above could you please provide the details of what the service was and why you stopped offering the service?

Q15. What University are you from?

Q16. How many campuses does your university have?

Q17. Approximately how many students are enrolled at your university?

Q18. What types of programs are available at your university?

Q19. How many full-time equivalent counsellor positions do you have at your university?

Q20. How many of these counsellor positions are permanent?

Q21. What types of services does the counselling service at your university offer?

Q22. What is your current wait time for an initial counselling appointment?

Q23. Are there any further comments you would like to offer? 